\title{
Antiproliferative activity, mechanism of action and oral antitumor activity of CP-4126, a fatty acid derivative of gemcitabine, in in vitro and in vivo tumor models
}

\author{
Andries M. Bergman • Auke D. Adema • Jan Balzarini • Skjalg Bruheim • \\ Iduna Fichtner • Paul Noordhuis • Øystein Fodstad • Finn Myhren • \\ Marit L. Sandvold • Hans R. Hendriks • Godefridus J. Peters
}

Received: 4 November 2009 / Accepted: 11 December 2009/Published online: 12 January 2010

(C) The Author(s) 2009. This article is published with open access at Springerlink.com

\begin{abstract}
Summary Gemcitabine is a deoxycytidine (dCyd) analog with activity in leukemia and solid tumors, which requires phosphorylation by deoxycytidine kinase (dCK). Decreased membrane transport is a mechanism of resistance to gemcitabine. In order to facilitate gemcitabine uptake and prolong retention in the cell, a lipophilic pro-drug was synthesized (CP-4126), with an elaidic fatty acid esterified at the 5'position. CP-4126 was tested in cell lines resistant to cytarabine, another dCyd analog or gemcitabine. Activity of gemcitabine and the derivative was comparable in the
\end{abstract}

Andries M. Bergman and Auke D. Adema contributed equally to this paper.

A. M. Bergman · A. D. Adema • P. Noordhuis · G. J. Peters $(\bowtie)$ Department of Medical Oncology, VU University Medical Center, P.O. Box 7057, 1007 MB Amsterdam, The Netherlands

e-mail: gj.peters@vumc.nl

\section{J. Balzarini}

Rega Institute for Medical Research,

Katholieke Universiteit Leuven,

Leuven, Belgium

S. Bruheim $\bullet \varnothing$. Fodstad

Radium Hospital,

Oslo, Norway

I. Fichtner

Max-Delbrück-Center for Molecular Medicine,

Berlin-Buch, Germany

F. Myhren • M. L. Sandvold

Clavis Pharma,

Oslo, Norway

H. R. Hendriks

Hendriks Pharmaceutical Consulting,

Purmerend, The Netherlands parent cell lines, while in dCK deficient cells all compounds were inactive. However, inhibition of nucleoside transport increased the $\mathrm{IC}_{50}$ for gemcitabine up to 200-fold, but not for CP-4126, underlining the independence of a nucleoside transporter. For in vivo evaluation, nude mice bearing a human xenograft were treated intraperitoneally every third day for five doses at the maximal tolerated dose. In melanoma, sarcoma, lung, prostate, pancreatic and breast cancer xenografts, gemcitabine and CP-4126 were equally and highly effective; in four other xenografts moderately but equally active. In contrast to gemcitabine, CP-4126 could be administered orally, with a schedule and dose dependent toxicity and antitumor activity. In a colon cancer xenograft, antitumor activity of orally administered CP-4126 was equal to the intraperitoneally administered drug. In conclusion, CP4126 is membrane transporter independent. Intraperitoneally administered CP-4126 was as effective as gemcitabine in several xenografts and CP-4126 is tolerated when orally administered. CP-4126 seems to be a promising new anticancer drug.

Keywords Gemcitabine - Gemcitabine derivative · Drug sensitivity - Deoxycytidine deaminase - Drug accumulation . Drug retention $\cdot$ DNA damage $\cdot$ RNA damage

\section{Introduction}

Gemcitabine $\left(2^{\prime}, 2^{\prime}\right.$-difluorodeoxycytidine, $\left.\mathrm{dFdC}\right)$ is a dCyd analog, which is active against several types of solid tumors, including Non-Small Cell Lung Cancer (NSCLC) and pancreatic carcinoma [1-4]. Gemcitabine requires phosphorylation by deoxycytidine kinase (dCK) in order to be active, and can be inactivated by deamination by 
deoxycytidine deaminase (dCDA) to $2^{\prime}, 2^{\prime}$-difluorodeoxyuridine $(\mathrm{dFdU})$ [5]. After conversion by kinases to its active form, $2^{\prime}, 2^{\prime}$-difluorodeoxycytidine triphosphate (dFdCTP), it can be incorporated into DNA and is a potent inhibitor of DNA-synthesis by inhibition of DNA polymerase $[6,7]$. Moreover, gemcitabine, as $\mathrm{dFdCTP}$, is also incorporated into RNA [8].

The inherent or acquired resistance of tumors to cytostatic agents is a major clinical problem. Like other nucleoside analogs, gemcitabine is hydrophilic and cannot traverse cell membranes by passive diffusion [9]. Specialized transport systems are required for the passage of nucleoside analogs in or out of the cell [10]. Altered nucleoside transport activity as a mechanism of drug resistance has been described for gemcitabine and the structurally and functionally related cytarabine (ara-C) $[11,12]$.

Since decreased sensitivity to gemcitabine might be the result of reduced drug accumulation, a fatty acid ester derivative of gemcitabine CP-4126 was synthesized (Fig. 1a). The derivative was intended to facilitate the increased accumulation and retention of gemcitabine in the tumor cells. A similarly esterified cytarabine derivative, CP-4055, appeared to be one of the most promising lipophilic cytarabine pro-drugs, which enhanced retention of the drug effects $[13,14]$. This drug now has shown acceptable tolerability in phase I studies [15] and is currently tested in phase II studies on solid tumors and leukemia. In CP-4126, the elaidic acid (trans-9-octadecenoic fatty acid) was coupled to the $5^{\prime}$ position on the sugar moiety. In the cell, CP-4126 needs to be converted to gemcitabine by esterases in order to be phosphorylated. In this paper we describe cytotoxicity of CP-4126 in cytarabine and gemcitabine sensitive and resistant cell lines, independency of membrane transport systems, the modulation of dCDA activity and its in vivo activity against human tumor xenografts when administered both intraperitoneally (ip) and orally.

\section{Materials and methods}

\section{Materials}

Dulbecco's Modified Eagle's Medium (DMEM) and RPMI1640 were purchased from Flow Laboratories (Irvine, UK) and fetal calf serum (FCS) from Gibco (New York, USA), Rat serum was purchased from Harlan/Olac (Zeist, the Netherlands), trichloroacetic acid (TCA), glutamine and gentamycin from Merck (Darmstadt, Germany), trypsin, sulforhodamine B (SRB), NBMPR and dipyridamole from Sigma-Aldrich (St. Louis, MO, USA). Gemcitabine was obtained from the local pharmacy department. CP-4126 was provided by Clavis Pharma (Oslo, Norway). $\left[2-{ }^{14} \mathrm{C}\right]-$
TdR, $62.8 \mathrm{mCi} / \mathrm{mmol}$ was purchased from Dupont de Nemours NEND (Dreiech, Germany) and $\left[5-{ }^{3} \mathrm{H}\right]-\mathrm{UR}$, $27.0 \mathrm{Ci} / \mathrm{mmol}$ from Amersham (Buckinghamshire, UK) and propanidid from Sombrevin; Gedeon Richter Ltd. (Budapest, Hungary). All other chemicals were of analytical grade and commercially available.

Preparation of the test samples

CP-4126 was dissolved in DMSO to a final concentration of $20 \mathrm{mM}$. Serial dilutions ranging from $8 \cdot 10^{-10} \mathrm{M}$ to $10^{-3} \mathrm{M}$ were prepared of the stock solution in cell culture medium. Drug concentrations $>10^{-3} \mathrm{M}$ could not be obtained due to precipitation of the compound in the wells. Moreover, at a concentration of $2.10^{-3} \mathrm{M}$ cells would be exposed to a toxic concentration of DMSO $(>1 \%)$; therefore concentrations were chosen in a range that would never expose cells to more than $1 \%$ DMSO. The stock solutions of gemcitabine and $\mathrm{CP}-4126$ were stored at $-20^{\circ} \mathrm{C}$. $\mathrm{CP}-4126$ for animal experiments was supplied as a ready to use, sterile, colloidal suspension, stored at $2-8^{\circ} \mathrm{C}$.

\section{Cell culture}

The in vitro experiments were performed in cell lines of leukemic and solid tumor origin, both sensitive and resistant to gemcitabine. Murine leukemia L1210 cells, used as its variant L5, and the cytarabine resistant variant L4A6 were routinely cultured in suspension in RPMI-1640 medium supplemented with $10 \%$ fetal calf serum (FCS), $60 \mu \mathrm{M} 2-\beta$-mercaptoethanol and $250 \mathrm{ng} / \mathrm{ml}$ gentamicin, as described previously [16]. Rat leukemia BCLO cells were cultured in RPMI-1640 medium, as described [17], supplemented with $3.2 \mathrm{mM}$ L-glutamine, 10\% FCS and $250 \mathrm{ng} / \mathrm{ml}$ gentamicin, the cytarabine resistant variant Bara-C was cultured in the same medium as BCLO, but instead of $10 \%$ FCS, supplemented with 5\% FCS and 5\% rat serum. BCLO and Bara-C were generously provided by Dr L. Colly (then at Dept. Hematology, University Hospital Leiden, the Netherlands). The solid tumor cell lines were A2780, a human ovarian cancer cell line [18] and its variant AG6000, which is highly resistant to gemcitabine [19]. The murine colon cancer cell lines $\mathrm{C} 26-\mathrm{A}$ and $\mathrm{C} 26-\mathrm{G}$ were derived from the murine Colon 26-A tumor and its variant Colon 26-G with an in vivo induced resistance to gemcitabine, respectively [20]. The resistance was related to overexpression of ribonucleotide reductase subunit M1 (RRM1) RNA [21]. These and the other solid tumor cell lines were grown as monolayers in DMEM supplemented with $5 \% \mathrm{FCS}$, and $250 \mathrm{ng} / \mathrm{ml}$ gentamicin. Characteristics of the other models are summarized in the results. All cell lines were characterized as described earlier [13, 14, 16-23]. 
a

\begin{tabular}{llll}
\hline Compound & $\begin{array}{l}\text { double chain Structure R } \\
\text { bonds }\end{array}$ & length
\end{tabular}

(n)

$\begin{array}{lll}\mathrm{CP}-4126 & 1 & 18\end{array}$

gemcitabine 0

0

H

b

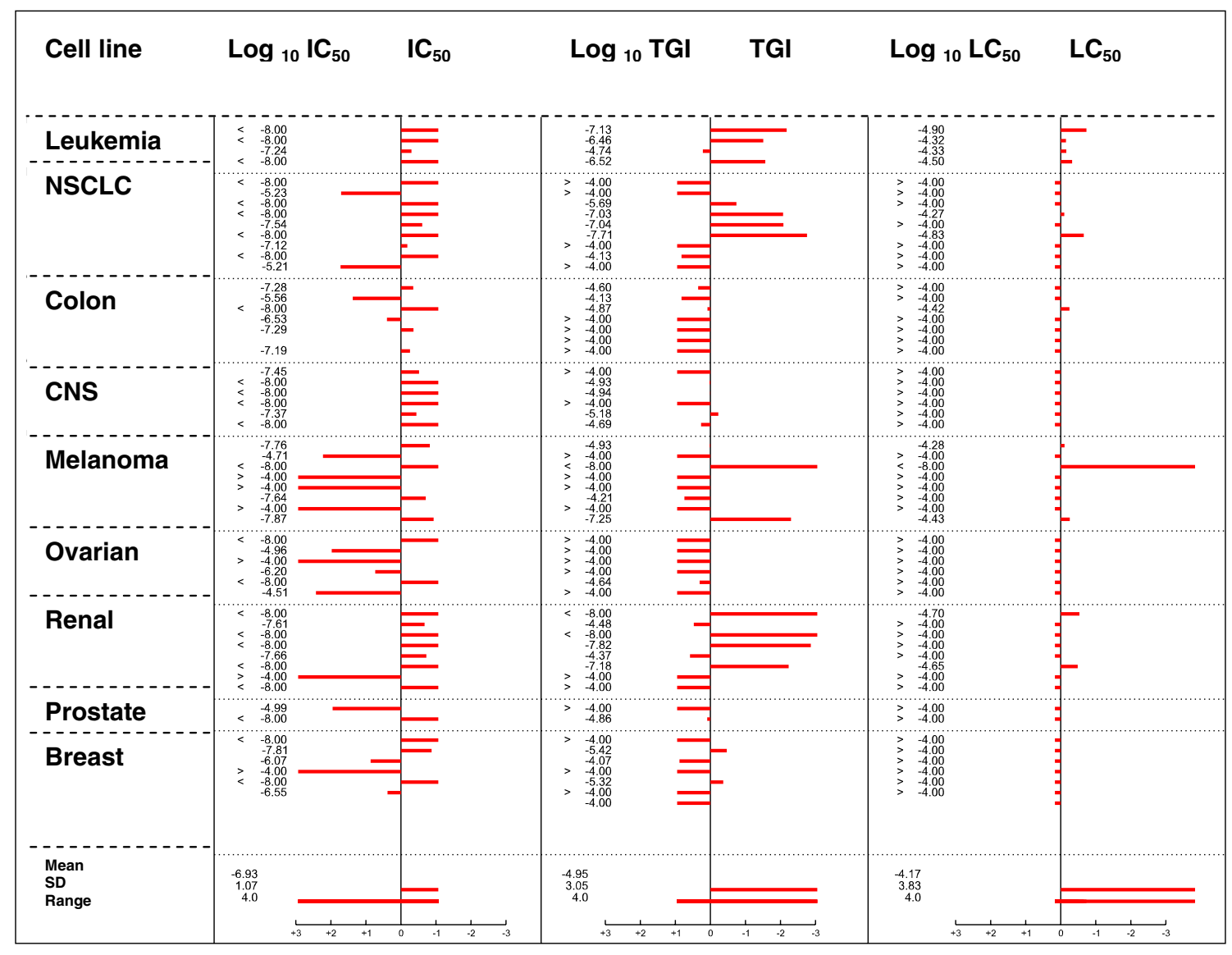

C

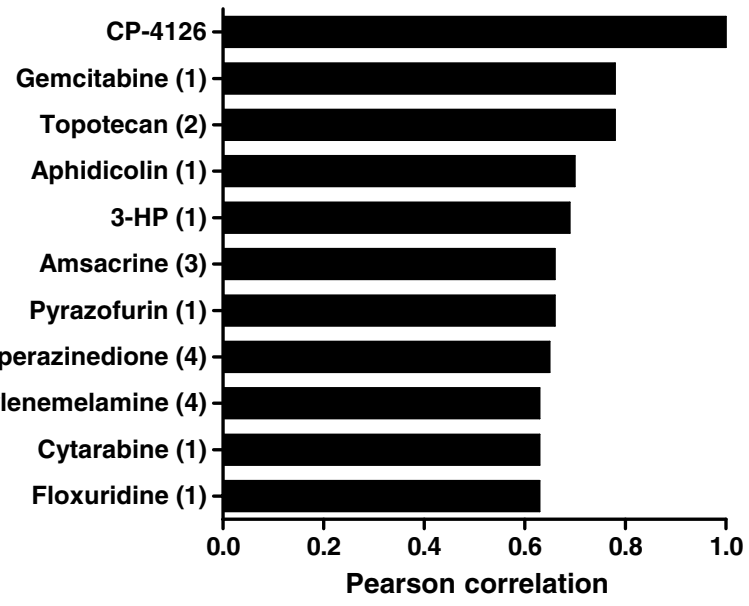


Fig. 1 a Chemical structure of gemcitabine and the fatty acid derivative CP-4126. b Mean $\mathrm{IC}_{50}$, TGI and $\mathrm{LC}_{50}$ graphs of CP-4126 on the NCI60 cell lines. Values represent Log values (M). Bars represent deviations of the means of all tested cell lines. Over all 60 cell lines the average $\mathrm{IC}_{50}$ for $\mathrm{CP}-4126$ was $0.1 \mu \mathrm{M}$, the TGI $12.6 \mu \mathrm{M}$ and the $\mathrm{LC}_{50} 70.9 \mu \mathrm{M}$. For $\mathrm{dFdC}$ the $\mathrm{IC}_{50}$ was $0.2 \mu \mathrm{M}$, the TGI $0.9 \mu \mathrm{M}$ and the $\mathrm{LC}_{50} 1.0 \mu \mathrm{M}$. The $\mathrm{dFdC}$ data were obtained from the NCI60 database (dtp.nci.nih.gov), which also lists the separate disease specific cell lines. c COMPARE analysis of CP-4126 (NSC 735837) with standard agents of the NCI database including gemcitabine (NSC613327). 1 DNA antimetabolite, 2 topoisomerase 1 inhibitor, 3 topoisomerase 2 inhibitor, 4 alkylating agent

The effect of the nucleoside transport inhibitors nitrobenzylthioinosine (NBMPR) and dipyridamole on sensitivity to gemcitabine and CP-4126 were studied in the human malignant melanoma cells THX and LOX and the human Tcell leukemia's MOLT4 and MOLT4/clone8 [22]. These cells were grown in suspension in RPMI-1640 based growth medium.

All populations were cultured at $37^{\circ} \mathrm{C}$ in a humidified atmosphere of $95 \%$ air and $5 \% \mathrm{CO}_{2}$ and regularly screened for Mycoplasma contamination by using a rapid detection system with a ${ }^{3} \mathrm{H}$-labelled DNA probe (Gen-Probe, San Diego, CA, USA) and were found to be negative.

\section{Chemosensitivity tests}

Sensitivity to drugs was defined by the concentration of the drug causing a growth inhibition of $50 \%\left(\mathrm{IC}_{50}\right)$ after $72 \mathrm{~h}$ drug exposure of the cells. Determination of growth inhibition in the L1210, L4A6, BCLO and Bara-C leukemia cells growing in suspension was performed by a cell counting method as previously described [23]. The cells were plated in 24-well plates in different densities, depending on their doubling times, to enable log linear growth for $72 \mathrm{~h}$ (L5, 50,000 cells/ well; L4A6, 100,000 cells/well; BCLO, 150,000 cells/well; Bara-C, 175,000 cells/well). Drugs were added directly after plating the cells. Final concentrations of the drugs in the wells ranged from $2 \cdot 10^{-10}$ to $10^{-3} \mathrm{M}$.

For the studies on the effect of nucleoside transport inhibitors on drug sensitivity, cells were plated at a density of $2.5 .10^{5}$ cells $/ \mathrm{ml}$. The nucleoside transport carrier inhibitors NBMPR and dipyridamole were used at subtoxic levels (100 $\mu \mathrm{M}$ and $4 \mu \mathrm{g} / \mathrm{ml}$, respectively) and gemcitabine and CP-4126 were added at serial dilutions in the appropriate concentration range.

All experiments were terminated after $72 \mathrm{~h}$ and the growth rate was determined by cell counting using a Sysmex Microcell counter. Growth inhibition curves were made relative to the control of every assay. Two control values were always included; the number of cells plated at the day of drug administration (set at $0 \%$ ) and that of cells after $72 \mathrm{~h}$ not exposed to drugs (set at $100 \%$ ). Straight lines connected the points, and the $\mathrm{IC}_{50}$ values were determined from the interpolated graph.
The determination of the $\mathrm{IC}_{50}$ in the monolayer solid tumor cells was performed using the SRB assay [24, 25]. On day one $100 \mu \mathrm{l}$ cell suspension was plated per well in 96 well plates (A2780 6,000 cells/well, AG6000 18,000 cells/well, C26-A 5,000 cells/well, C26-G 8,000 cells/well), followed by $100 \mu \mathrm{l}$ of a serial drug dilution at day two. The final concentrations of the drugs in the wells ranged from $2.10^{-10}$ to $2.10^{-3} \mathrm{M}$. Cells were exposed to the drugs for $72 \mathrm{~h}$, allowing at least two doubling times. After exposure, cells were precipitated with $50 \mu \mathrm{l}$ ice-cold $50 \% \mathrm{w} / \mathrm{v}$ TCA (trichloro acetic acid) and fixed for $60 \mathrm{~min}$ after which the SRB assay was performed as described [26]. Growth inhibition curves were made by calculation of the relative growth based on the optical densities of drug-treated and control wells of every SRB assay. Straight lines connected the points and the $\mathrm{IC}_{50}$ values were determined from the interpolated graph [26].

\section{NCI in vitro screen}

The cytotoxicity profile of CP-4126 (NSC number 735837) was also studied in the in vitro screen of the US National Cancer Institute (NCI). Detailed descriptions of the standard technical procedures and data analyses performed by the NCI have been published elsewhere [27, 28] and on their website http://dtp.nci.nih.gov/index.html. Briefly, the assay involves plating the cells, preincubation for $24 \mathrm{~h}$, followed by $48 \mathrm{~h}$ continuous drug exposure over a broad concentration range against a panel of 60 cell lines comprising nine different tumor types. The cytotoxicity was assessed with the sulforhodamine B (SRB) protein assay. Percentage growth is based on optical measurements and the response parameters $50 \%$ growth inhibition $\left(\mathrm{GI}_{50}\right.$, corresponding to the $\mathrm{IC}_{50}$ which is used hereafter to avoid confusion), total growth inhibition (TGI) and 50\% lethal concentration $\left(\mathrm{LC}_{50}\right)$ are interpolated values representing the concentrations at which the percentage growth is $+50,0$ and $-50 \%$, respectively, at the end of the experiments compared with the start. The $\mathrm{LC}_{50}$ indicates $50 \%$ cell kill, and is used by the NCI as an indication of cytotoxicity. The results are presented in the form of mean graphs in which drug effects are calculated as positive or negative deviations from the average sensitivity of the entire cell line panel. The COMPARE algorithm of the growth inhibition $\left(\mathrm{IC}_{50}, \mathrm{TGI}\right)$ and the cytotoxicity $\left(\mathrm{LC}_{50}\right)$ profile can be used to obtain an indication of the mechanism of action of the compound tested (http://dtp.nci.nih.gov/docs/ compare/compare.html).

\section{Deoxycytidine deaminase activity}

The effect of the derivatives on purified deoxycytidine deaminase (dCDA) was determined as described earlier [14, 
29]. Briefly, enzyme activity was determined at $37^{\circ} \mathrm{C}$ with purified enzyme at $500 \mu \mathrm{M}$ dCyd or gemcitabine as a substrate and $500 \mu \mathrm{M}$ the competitive compound (gemcitabine and CP-4126). A blank without substrate and inhibitor and a control with a substrate but without an inhibitor was included in every experiment. After 15 or 25 min incubation precipitation of the proteins by addition of $40 \% \mathrm{w} / \mathrm{v}$ TCA terminated the reaction. The supernatant was neutralized with trioctylamine/1,1,2trichloro-trifluoroethane $(\mathrm{v} / \mathrm{v}$ : 4/1). The upper, aqueous layer containing the substrate $\mathrm{dCyd}$ or gemcitabine and their respective products deoxyuridine or $2^{\prime}, 2^{\prime}$ difluorodeoxyuridine, was analyzed using reversed phase HPLC [29].

\section{Animals and xenograft testing}

Female BALB/c nude (nu/nu) mice were used, 5-8 weeks of age at the start of the experiment (20-27 g). The animals were maintained under specific pathogen-free conditions, and food and water were supplied ad libitum. Housing and all procedures involving animals were performed according to protocols approved by the animal care and use committee, in compliance with the Norwegian and German National Committees for Animal Experiments guidelines on animal welfare. Mice were anaesthetized with $5 \mathrm{mg} / 10 \mathrm{~g}$ propanidid, given ip before tumor tissue implantation. The panel of human solid tumor xenografts consisted of a malignant melanoma (THX), one small cell lung carcinoma (H-146), one non-small cell lung adenocarcinoma (EKVX), one osteosarcoma (OHS), one malignant fibrous histiocytoma (TAXII-1) one non-classifiable sarcoma (MHMX), one breast cancer (MA-11), one prostate cancer (CRL1435), two pancreas cancer models (PANC-1 and MiaPaCa-2) and one patient-derived [30] colon cancer (Co6044). Tumor fragments of about $2 \times 2 \times 2 \mathrm{~mm}$, were implanted subcutaneously into each flank of female nude mice. At the start of treatment, the minimum tumor diameter was $4 \mathrm{~mm}$, equivalent to a volume of $32 \mathrm{~mm}^{3}$. If a mouse died within 2 weeks after the final drug injection, it was considered a toxic death, and the animal excluded from the study. Treatment causing more than median $10 \%$ body weight loss, compared with controls, was considered not evaluable for antitumor efficacy. Tumor volume was calculated according to the formula: tumor volume $=$ $0.5 \times$ length $\times$ width $^{2}$. Relative Tumor Volumes (RTVs), were calculated for each individual tumor by dividing the tumor volume on day $\mathrm{X}\left(\mathrm{V}_{\mathrm{x}}\right)$ by the tumor volume on day $0\left(\mathrm{~V}_{0}\right)$ multiplied by $100 \%$. The tumor volume of a treatment group was expressed as the median RTV of all mice of the group. The drug effects were calculated from growth curves constructed on the basis of median RTVs. Two different methods of antitumor evaluation were used; by calculation of the $\mathrm{T} / \mathrm{C}$ values, i.e. by dividing the $\mathrm{RTV}$ of treated mice by that of control mice X $100 \%$; and by the Specific Growth Delay Factor (SGD) which was defined as the mean number of tumor-doubling times gained by the treatment and was calculated with the formula: $\mathrm{SGD}=\left(\mathrm{TD}_{\mathrm{tr}}--\mathrm{TD}_{\text {con }}\right) / \mathrm{TD}_{\text {con }}$. In this formula $\mathrm{TD}_{\text {tr }}$ is the tumor doubling time of treated tumors and $\mathrm{TD}_{\mathrm{con}}$ that of untreated tumors. A T/C $\%$ of $<25 \%$ and a SGD $>2$ were considered as active.

Mice were treated both ip and by oral gavage. CP4126 was used as a liposomal formulation, similar to that used in clinical studies. Gemcitabine was also used as the clinical formulation. Dose finding and scheduling studies were performed in order to determine the maximum tolerated dose (MTD) for the test compounds using ip administration every 3 days for five doses (q3dx5) in the range of $25-120 \mathrm{mg} / \mathrm{kg}$ for CP-4126 and $90-150 \mathrm{mg} / \mathrm{kg}$ for gemcitabine, which is also the optimal schedule for i.p. and i.v. gemcitabine in mice [20, 31]. Similarly, for oral administration of both gemcitabine and CP-4126 (given by oral gavage), an every 3rd day schedule (qd 1, 4, 7, 10 and 13) was used. Since a continuous infusion of gemcitabine was more active then the every third day schedule [31], and a daily oral administration might mimic a continuous infusion we also tested oral CP-4126 at a daily schedule (qd 1-5). Since weekly administration is common clinical practice [4] we also tested a weekly (day 1 and 8) schedule. For ip administration the MTD (weight loss $<10 \%$ ) of CP-4126 was $40 \mathrm{mg} / \mathrm{kg}$ and $120 \mathrm{mg} / \mathrm{kg}$ for gemcitabine. Dose finding studies for oral administration are described in the results. In order to assess bio-availability of CP-4126 two male beagle dogs received a single dose of intravenous CP-4126 (4 mg/kg), followed after a wash-out period by a capsule of CP-4126 at the same dose $(30 \mathrm{mg})$. The weight of the animals at start was 7.06 and $7.17 \mathrm{~kg}$. Urine was sampled at intervals of $0-8 \mathrm{~h}$ and 8-24 h. Plasma and urine samples were analyzed for CP-4126 (plasma only), dFdC and dFdU using LC-MS-MS, essentially as described for CP-4055 [15]. The AUC was calculated using Win-Nonlin professional version 6 . The plasma pharmacokinetics was also determined on day 1 of a formal toxicology study, with three or five animals per group.

\section{Statistical analysis}

Differences in inhibition of dCDA activity were evaluated using $t$-test for unpaired data. The computer program SPSS (version 7.5, SPSS, Inc., Chicago, IL) was used for statistical analysis. Statistical analysis of differences in tumor size between each treated and the control group was performed with the non-parametric Mann-Whitney $U$ test at a cut-off level of $p<0.05$. 


\section{Results}

\section{Chemosensitivity tests}

The growth inhibitory effects of the compounds in the parental leukemia and solid tumor cells are listed in Table 1. The gemcitabine derivative CP-4126 was 1.7-fold less active in the leukemia L5 cells, but 2-fold more active than gemcitabine in BCLO cells and equally active in the solid tumor C26-A cells.

The L4A6 cells were less sensitive to the analog compared to the parent compound and comparable in Bara-C and C26-G cells. In AG6000 cells the sensitivity was also comparable, in line with the complete absence of dCK activity in this cell line [19], indicating the dependency of CP-4126 to be activated by $\mathrm{dCK}$.

To study the role of membrane transport for gemcitabine and CP-4126, differences in sensitivity to the drugs in the presence of nucleoside transport inhibitors were determined. In Table $1 \mathrm{IC}_{50}$ values are listed for gemcitabine and CP-4126 in human cancer cells with or without $100 \mu \mathrm{M}$ NBMPR or $4 \mu \mathrm{g} / \mathrm{ml}$ dipyridamole. In the THX human malignant melanoma cells NBMPR and dipyridamole decreased sensitivity to gemcitabine 55- and 115-fold, respectively, while sensitivity to CP-4126 was only decreased 1.6- and 1.3-fold, respectively. The largest difference was found in the MOLT4 human T-cell leukemia cells. NBMPR and dipyridamole decreased sensitivity to gemcitabine 273- and 203-fold, respectively, while NBMPR decreased sensitivity to $\mathrm{CP}$ 4126 only 1.8 -fold and no difference in sensitivity was found in the presence of dipyridamole. In the other cell lines tested a comparable pattern was found, suggesting a nucleoside transporter independent transport over the cell membrane of the fatty acid derivative CP-4126.

\section{$\mathrm{NCI}$ in vitro screen}

The cytotoxic activity of CP-4126 (NSC 735837) was evaluated in duplicate in the NCI in vitro screen. CP-4126 was tested at five concentrations ranging from $10^{-4}$ to $10^{-8} \mathrm{M}$ at one-log increments. The results of one assay are shown in Fig. 1b, the results of the second assay showed comparable results and are not shown. Leukemia appeared to be the most sensitive disease type, followed by renal cell cancer and NSCLC. Target analysis (http://tp.nci.nih.gov/ mtargets/mt_index.html) for the nucleoside transporter hENT in the NCI screen for hENT showed a low expression for renal cancer and NSCLC, while breast cancer and leukemia showed a high expression of hENT. Together this indicates no correlation of the cell lines in the NCI screen between $\mathrm{CP}-4126$ sensitivity (evaluated as $\mathrm{IC}_{50}$ and $\mathrm{TGI}$ ) and hENT expression.

A COMPARE analysis of the $\mathrm{IC}_{50}$ profile of $\mathrm{CP}-4126$ against the profiles of 170 compounds in the standard agent
Table 1 Activity of CP-4126 in gemcitabine sensitive and resistant cell lines; role of dCK deficiency and the effect of the nucleoside transport inhibitors NBMPR and dipyridamole on the cytotoxic activity of gemcitabine and its analog CP-4126 in different cell lines

L1210: murine leukemia, BCLO: rat leukemia, C26-A: murine colon carcinoma, A2780: human ovarian cancer, THX: human malignant melanoma, LOX: human malignant melanoma, EKVX: human lung adenocarcinoma, MOLT4:

human T-cell leukemia, MOLT4/clone8: human T-cell leukemia. Values are means in $\mu \mathrm{M} \pm \mathrm{SEM}$ of three experiments

${ }^{a}$ NBMPR in a concentration of $100 \mu \mathrm{M}$

${ }^{\mathrm{b}}$ Dipyridamole in a concentration of $4 \mu \mathrm{g} / \mathrm{ml}$

\begin{tabular}{|c|c|c|c|}
\hline \multirow[t]{2}{*}{ Cell line } & \multirow[t]{2}{*}{ Nucleoside transport inhibitor } & \multicolumn{2}{|l|}{$\mathrm{IC}_{50}(\mu \mathrm{M})$} \\
\hline & & gemcitabine & CP-4126 \\
\hline L1210/L5 & & $0.0019 \pm 0.0006$ & $0.0033 \pm 0.0019$ \\
\hline L4A6 & & $8.8 \pm 3.6$ & $16 \pm 6$ \\
\hline BCLO & & $0.0083 \pm 0.0009$ & $0.0042 \pm 0.0029$ \\
\hline Bara-C & & $12.7 \pm 2.2$ & $13.0 \pm 2.0$ \\
\hline C26-A & & $0.016 \pm 0.004$ & $0.0015 \pm 0.0006$ \\
\hline C26-G & & $0.02 \pm 0.01$ & $0.03 \pm 0.02$ \\
\hline A 2780 & & $0.0015 \pm 0.0006$ & $0.0025 \pm 0.0005$ \\
\hline AG6000 & & $185 \pm 108$ & $91 \pm 6$ \\
\hline \multirow[t]{3}{*}{ THX } & & $0.0027 \pm 0.0007$ & $0.0040 \pm 0.0016$ \\
\hline & $+\mathrm{NBMPR}^{\mathrm{a}}$ & $0.15 \pm 0.05$ & $0.0063 \pm 0.0051$ \\
\hline & + Dipyridamole $^{\mathrm{b}}$ & $0.31 \pm 0.13$ & $0.0053 \pm 0.0037$ \\
\hline \multirow[t]{3}{*}{ LOX } & & $0.0047 \pm 0.0010$ & $0.0077 \pm 0.0028$ \\
\hline & +NBMPR & $1.15 \pm 0.06$ & $0.027 \pm 0.0006$ \\
\hline & +Dipyridamole & $0.61 \pm 0.22$ & $0.025 \pm 0.001$ \\
\hline \multirow[t]{3}{*}{ MOLT4 } & & $0.0030 \pm 0.0033$ & $0.028 \pm 0.0035$ \\
\hline & +NBMPR & $0.82 \pm 0.25$ & $0.051 \pm 0.033$ \\
\hline & +Dipyridamole & $0.61 \pm 0.26$ & $0.021 \pm 0.002$ \\
\hline \multirow[t]{3}{*}{ MOLT4/C8 } & & $0.46 \pm 0.12$ & $0.088 \pm 0.013$ \\
\hline & +NBMPR & $8.31 \pm 1.20$ & $0.12 \pm 0.05$ \\
\hline & +Dipyridamole & $7.62 \pm 0.59$ & $0.098 \pm 0.030$ \\
\hline
\end{tabular}


NCI database was performed, as well as a COMPARE analysis to all compounds in the NCI database where gemcitabine was also included. The correlation coefficient for CP-4126 was equal for the correlation with gemcitabine and topotecan, followed by aphidicolin and 3-HP (Fig. 1c). Mechanistically most compounds in the top ten are DNA interactors, of which five are DNA antimetabolites like gemcitabine. The structurally related compounds and antimetabolites cytarabine and floxuridine are found at the end of the top ten list.

Effect of fatty acid derivatives on deoxycytidine deaminase activity

To study the effect of the fatty acid derivative on deamination of $\mathrm{dCyd}$ and gemcitabine, purified dCDA enzyme was incubated with dCyd (312 pmol/hr/ $\mu$ l enzyme) or gemcitabine ( $624 \mathrm{pmol} / \mathrm{hr} / \mu \mathrm{l}$ enzyme) as a substrate and with CP-4126 as the test compound. CP-4126 was not detectable in the chromatograms using the applied separation system. Purified dCDA did not catalyze degradation of CP-4126, since neither the parent nucleoside gemcitabine nor its deaminated derivative $\mathrm{dFdU}$ were detected. This means that any observed effect of CP-4126 would be a direct effect on dCDA. When dCyd and gemcitabine were added simultaneously, only dFdU was found $(1,127 \mathrm{pmol} /$ $\mathrm{hr} / \mu \mathrm{l}$ enzyme), demonstrating that gemcitabine is a much better substrate for dCDA then dCyd. CP-4126 itself inhibited deamination of dCyd completely $(<1)$ and deamination of gemcitabine by $47.2 \%$.

\section{Antitumor activity in sc models}

Table 2 summarizes the effects of ip administered CP4126 in inhibiting the growth of solid tumor xenografts. The choice of the xenografts was dependent on the availability of models and therefore they do not completely overlap with the in vitro models. Furthermore not all in vitro models were available as in vivo models. In the EKVX, non-small cell lung cancer xenograft, gemcitabine and CP-4126 were equally effective, with $\mathrm{T} / \mathrm{C}$ values of $3.4 \%$ and $2.9 \%$, respectively. In the $\mathrm{H}-146$ small cell lung cancer xenograft gemcitabine and CP4126 were not active. Both gemcitabine and CP-4126 were highly active in the MHMX non-classifiable sarcoma xenograft, but CP-4126 showed the highest activity with a $\mathrm{T} / \mathrm{C}$ of $1.1 \%$ and a SGD $>12.8$. Gemcitabine was inactive in the TAX II-1 fibrous histiocytoma xenograft, whereas CP-4126 exerted some activity. In the OHS osteosarcoma xenograft both compounds were inactive. Gemcitabine was the most active agent against the THX malignant melanoma xenograft with a $\mathrm{T} / \mathrm{C}$ of $1.2 \%$ and a SGD of $>6.25$, whereas for
CP-4126 a T/C of $6.8 \%$ and a SGD $>2.7$ were found. In the MA-11 breast cancer xenograft only gemcitabine exerted some activity. In the CRL-1435 prostate cancer xenograft, gemcitabine and CP-4126 were both active compounds with SGDs of 2.9 and 3.2, respectively. In the pancreas xenografts MiaPaCa- 2 and PANC-1 gemcitabine was poorly tolerated with toxic deaths of $7 / 7$ and $4 / 9$, respectively. In the MiaPaCa-2 model CP-4126 was tolerated with a weight loss of $0.4 \%$, but had no antitumor activity. In PANC-1 CP-4126 was tolerated with a weight loss of $4.6 \%$ and had high antitumor activity with a T/C of $12 \%$ and SGD of 6.8 .

Antitumor activity and toxicity of orally administered CP-4126 and gemcitabine in the colon cancer xenograft Co6044 bearing mice are summarized in Table 3 and in Fig. 2. Toxicity of gemcitabine given orally at similar doses as the ip administration was highly unpredictable, and in general very toxic. Hence, no therapeutic efficacy could be achieved. In contrast, at a weekly schedule of two doses, CP-4126 at $50 \mathrm{mg} / \mathrm{kg}$ was not toxic, but also not very effective (T/C of $22 \%$ ), while at $100 \mathrm{mg} / \mathrm{kg}$ toxicity was acceptable with a T/C of $4 \%$. At $150 \mathrm{mg} / \mathrm{kg}$ toxicity was unacceptable with $3 / 7$ deaths. In an every third day schedule (five doses) acceptable toxicity and significant antitumor activity was found at doses of 10,15 and $20 \mathrm{mg} \mathrm{CP}-4126 / \mathrm{kg}$. At a dose of $40 \mathrm{mg} / \mathrm{kg}$, a T/C of $5 \%$ was found with unacceptable toxicity. A dose of $10 \mathrm{mg}$ CP-4126/kg given at a daily schedule (q3dx5) showed a favorable toxicity and antitumor activity (Table 3), while a daily dose of $15 \mathrm{mg} / \mathrm{kg}$ was highly toxic (data not shown).

Antitumor activity and toxicity of orally administered CP-4126 and gemcitabine in the non-small cell lung cancer xenografts EKVX and MAKSAX are summarized in Table 3. For EKVX a daily dose of $10 \mathrm{mg} / \mathrm{kg} \mathrm{CP}-4126$ was too toxic for evaluation. A schedule of five times every 3 days (q3dx5) with $15 \mathrm{mg}$ CP-4126/kg did not produce a large antitumor effect, but had a favorable toxicity. The dose of $20 \mathrm{mg} / \mathrm{kg}$ did increase the antitumor effect but also the toxicity. For the MAKSAX tumor the higher dose of $22.5 \mathrm{mg} / \mathrm{kg}$ five times every 3 days CP4126 caused acceptable toxicity with a good antitumor effect.

The oral bioavailability of CP-4126 was evaluated in two dogs. CP-4126 was not detectable in plasma after oral administration, while it was detectable after i.v. administration. Levels of $\mathrm{dFdC}$ were higher than after i.v. administration, but those of dFdU were lower. In line with the latter finding excretion of $\mathrm{dFdU}$ in the urine was higher after i.v. than after oral administration (Table 4). The half-life of $\mathrm{dFdC}$ after iv administration of CP-4126 to dogs was longer than that after administration of $\mathrm{dFdC}$ to dogs (unpublished data), mice and humans [5, 31-33]. 
Table 2 Antitumor efficacy of ip administered gemcitabine and $\mathrm{CP}-4126$ in various human xenografts

Mice were treated ip every third day for five doses at the Maximum Tolerated Dose. Antitumor effect was expressed as $\mathrm{T} / \mathrm{C} \%$ (treated tumor size/control tumor size) $\times 100 \%$ and SGD (Specific Growth Delay). A $\mathrm{T} / \mathrm{C} \%<25 \%$ and an $\mathrm{SGD}>2$ were considered as active. Depending on the model 1-2 tumors were implanted in each mouse in each flank in the thoracic area. EKVX: non-small cell lung adenocarcinoma, H-146: small cell lung cancer, MHMX: non-classifiable sarcoma, TAXII-1: malignant fibrous histiocytoma, OHS: osteosarcoma, THX: malignant melanoma, MA-11: breast cancer, CRL-1435: prostate cancer; PANC-1; MiaPaCa2: pancreatic cancer

\begin{tabular}{|c|c|c|c|c|c|c|}
\hline \multirow[t]{2}{*}{ Tumor } & \multirow[t]{2}{*}{ Compound } & \multirow[t]{2}{*}{ Number of tumors } & \multicolumn{2}{|c|}{ Toxicity } & \multicolumn{2}{|c|}{ Antitumor effect } \\
\hline & & & Deaths & Mean weight loss (\%) & $\mathrm{T} / \mathrm{C}(\%)$ & SGD \\
\hline \multirow[t]{2}{*}{ EKVX } & gemcitabine & 9 & $0 / 6$ & 0.3 & 3 & 3.4 \\
\hline & CP-4126 & 9 & $0 / 6$ & 0 & 7 & 2.9 \\
\hline \multirow[t]{2}{*}{ H-146 } & gemcitabine & 7 & $0 / 6$ & 0.3 & 59 & 0.8 \\
\hline & CP-4126 & 7 & $0 / 6$ & 0 & 59 & 0.3 \\
\hline \multirow[t]{2}{*}{ MHMX } & gemcitabine & 9 & $2 / 7$ & 2.1 & 2 & $>7.2$ \\
\hline & CP-4126 & 9 & $1 / 6$ & 0 & 1 & $>12.8$ \\
\hline \multirow[t]{2}{*}{ TAX II-1 } & gemcitabine & 8 & $0 / 6$ & 0 & 53 & 0.5 \\
\hline & CP-4126 & 8 & $0 / 6$ & 0.7 & 30 & 1.3 \\
\hline \multirow[t]{2}{*}{ OHS } & gemcitabine & 14 & $0 / 9$ & 0 & 24 & 0.8 \\
\hline & CP-4126 & 13 & $1 / 9$ & 0 & 43 & 0.5 \\
\hline \multirow[t]{2}{*}{ THX } & gemcitabine & 16 & $0 / 8$ & 0 & 1 & $>6.25$ \\
\hline & CP-4126 & 16 & $0 / 8$ & 0 & 7 & $>2.7$ \\
\hline \multirow[t]{2}{*}{ MA-11 } & gemcitabine & 7 & $2 / 6$ & 7.7 & 7 & 1.8 \\
\hline & CP-4126 & 9 & $1 / 6$ & 0 & 29 & 0.7 \\
\hline \multirow[t]{2}{*}{ CRL-1435 } & gemcitabine & 7 & $3 / 7$ & 6.8 & 6 & 2.9 \\
\hline & CP-4126 & 9 & $3 / 8$ & 3.0 & 9 & 3.2 \\
\hline PANC-1 & CP-4126 & 7 & $0 / 6$ & 4.6 & 12 & 6.8 \\
\hline \multirow[t]{2}{*}{ MiaPaCa-2 } & gemcitabine & 7 & $4 / 9$ & 14.0 & 32 & 3.3 \\
\hline & CP-4126 & 14 & $1 / 9$ & 0.4 & 59 & 0.7 \\
\hline
\end{tabular}

\section{Discussion}

In this paper we describe the cytotoxic activity and mechanism of action of the gemcitabine derivative $\mathrm{CP}$ -
4126 in a panel of rodent, human leukemia and solid tumor cell lines and xenografts. The $\mathrm{IC}_{50}$ values of the gemcitabine derivative CP-4126 in the solid tumor cells were similar to those of gemcitabine; however, the derivative was
Table 3 Antitumor efficacy of orally administered CP-4126 and gemcitabine in the human colon cancer xenograft Co6044 and in the non-small cell lung cancer xenografts EKVX and MAKSAX

Antitumor effect was expressed as $\mathrm{T} / \mathrm{C}$ (treated tumor size/ control tumor size) in \%

$N A$ not applicable. Each mouse carried 1-2 tumors, depending on the take rate

\begin{tabular}{|c|c|c|c|c|c|}
\hline & \multicolumn{2}{|l|}{ Treatment } & \multirow[t]{2}{*}{ Deaths } & \multirow[t]{2}{*}{ Weight loss (\%) } & \multirow[t]{2}{*}{ Maximal T/C (\%) } \\
\hline & Schedule (days) & Dose (mg/kg) & & & \\
\hline & CP-4126 & & & & \\
\hline \multirow[t]{13}{*}{ Co6044 } & 1 and 8 & 50 & $0 / 7$ & 0 & 22 \\
\hline & 1 and 8 & 100 & $1 / 7$ & 4 & 4 \\
\hline & 1 and 8 & 150 & $3 / 7$ & 10 & 5 \\
\hline & $1,4,7,10$ and 13 & 10 & $0 / 7$ & 1 & 35 \\
\hline & $1,4,7,10$ and 13 & 15 & $0 / 7$ & 1 & 27 \\
\hline & $1,4,7,10$ and 13 & 20 & $1 / 7$ & 3 & 16 \\
\hline & $1,4,7,10$ and 13 & 40 & $2 / 8$ & 7 & 5 \\
\hline & 1 through 5 & 5 & $0 / 7$ & 3 & 20 \\
\hline & 1 through 5 & 10 & $0 / 7$ & 5 & 8 \\
\hline & gemcitabine & & & & \\
\hline & 1,4 and 7 & 40 & $5 / 7$ & 1 & 8 \\
\hline & 1,4 and 7 & 20 & $0 / 7$ & 0 & 29 \\
\hline & CP-4126 & & & & \\
\hline \multirow[t]{3}{*}{ EKVX } & 1 through 5 & 10 & $6 / 6$ & NA & NA \\
\hline & $1,4,7,10$ and 13 & 15 & $0 / 7$ & 0 & 74 \\
\hline & $1,4,7,10$ and 13 & 20 & $2 / 6$ & 10 & 63 \\
\hline \multirow[t]{2}{*}{ MAKSAX } & $1,4,7,10$ and 13 & 15 & $2 / 7$ & 18 & 62 \\
\hline & $1,4,7,10$ and 13 & 22.5 & $2 / 7$ & 18 & 37 \\
\hline
\end{tabular}




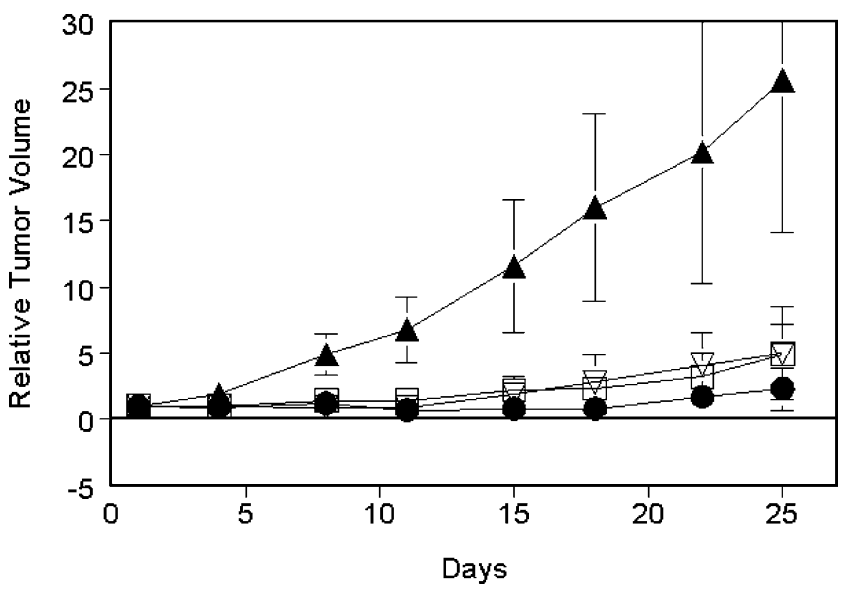

Fig. 2 Antitumor efficacy of CP-4126 as an oral drug in the human colon cancer xenograft Co6044. Mice treated with saline, qd 1-5 ( $\Delta$ ), $100 \mathrm{mg} / \mathrm{kg} \mathrm{CP-4126,} \mathrm{qd} \mathrm{1,7} \mathrm{( \bullet ),} 20 \mathrm{mg} / \mathrm{kg} \mathrm{CP-4126.} \mathrm{qd} \mathrm{1,} \mathrm{4,} \mathrm{7,} \mathrm{10,}$ $13,(\nabla)$ and $10 \mathrm{mg} / \mathrm{kg} \mathrm{CP}-4126$, qd 1-5 (口). The curve for the optimal schedule of gemcitabine (not shown) was in between that of the control and q3d schedule

more active in BCLO cells. Comparably a cytarabine derivative acylated at the 4-amino position N4-octadecyl1-beta-D-arabinosylcytosine was found to be equally active as cytarabine in several solid tumor and leukemia cell lines [34]. Several N4-acyl poly(ethyleneglycol) prodrugs of cytarabine exhibited superior activity compared to cytarabine in a solid lung tumor model [35].

The resistance to cytarabine in L4A6 and Bara-C cells is related to a decreased dCK activity [23]. In Bara-C cells cytarabine and gemcitabine resistance was related to a substrate dependent dCK deficiency. No dCK activity was found with cytarabine or gemcitabine as a substrate, but a normal activity with dCyd as a substrate [23]. CP-4126 was less active in solid tumor cells than the parental drug. In AG6000 cells, which are highly resistant to gemcitabine as a result of a dCK deficiency, no difference in sensitivity for either gemcitabine or CP-4126 was found, clearly confirming that CP-4126 is, like gemcitabine, also dependent upon activation by $\mathrm{dCK}$.

Since gemcitabine can be inactivated by deamination catalyzed by dCDA [5], we tested the effect of CP-4126 on deamination of dCyd and gemcitabine. Since gemcitabine is a better substrate CP-4126 inhibited deamination of dCyd completely and $\mathrm{dFdU}$ was formed, indicating competition for the enzyme [36, 37]. CP-4126 effectively inhibited deamination of dCyd and gemcitabine. Although theoretically inhibition of deamination of gemcitabine might result in higher drug levels and higher cytotoxicity, the role of dCDA in the development of resistance is not clear [38]. In vitro dCyd analogs are less effective in systems in which dCDA has a higher activity e.g. through transfection of the gene [33], and addition of a dCDA inhibitor increased activity of cytarabine and gemcitabine. A high dCDA activity will also affect gemcitabine pharmacokinetics, while clinically at a low dCDA activity gemcitabine causes higher toxicity [33, 39]. Since CP-4126 is not a substrate for dCDA and inhibits gemcitabine deamination a better bioavailability for gemcitabine derived from CP-4126 can be expected. In line with this finding the excretion of $\mathrm{dFdU}$ was lower in dogs after oral administration then after i.v. administration.

Since gemcitabine can be inactivated by deamination catalyzed by dCDA [5], we tested the effect of CP-4126 on deamination of dCyd and gemcitabine. Since gemcitabine is a better substrate CP-4126 inhibited deamination of dCyd completely and $\mathrm{dFdU}$ was formed, indicating competition for the enzyme [36, 37]. CP-4126 effectively inhibited deamination of $\mathrm{dCyd}$ and gemcitabine. Although theoretically inhibition of deamination of gemcitabine might result in higher drug levels and higher cytotoxicity, the role of dCDA in the development of resistance is not clear [38]. In vitro $\mathrm{dCyd}$ analogs are less effective in systems in which dCDA has a higher activity e.g. through transfection of the gene [33], and addition of a dCDA inhibitor increased activity of cytarabine and gemcitabine. A high dCDA activity will also affect gemcitabine pharmacokinetics, while clinically at a low dCDA activity gemcitabine causes higher toxicity $[33,39]$. Since CP-4126 is not a substrate for dCDA and inhibits gemcitabine deamination a better bioavailability for gemcitabine derived from CP-4126 can be expected. In line with this finding the excretion of $\mathrm{dFdU}$ was lower in dogs after oral administration then after i.v. administration.

Resistance of $\mathrm{C} 26-\mathrm{G}$ cells was associated with an increased RRM1 expression [21]. Since inhibitors of

Table 4 Bioavailability of orally administered CP-4126 in two dogs

\begin{tabular}{llllll}
\hline Compound & Dose & \multicolumn{2}{l}{ Plasma AUC } & & Urine excretion \\
\cline { 3 - 5 } & & CP-4126 $(\mu \mathrm{M} / \mathrm{h})$ & gemcitabine $(\mu \mathrm{M} / \mathrm{h})$ & $\mathrm{dFdU}(\mu \mathrm{M} / \mathrm{h})$ & $\mathrm{dFdU}(\%)$ \\
\hline $\mathrm{CP}-4126$ iv & $4 \mathrm{mg} / \mathrm{kg}$ & $3.2,2.5$ & $14.4,11.9$ & $65.4,52.3$ & $64.5,65.8$ \\
$\mathrm{CP}-4126$ oral & $4.3 \mathrm{mg} / \mathrm{kg}$ & 0,0 & $21.8,10.7$ & $55.0,60.1$ & $55.0,46.3$ \\
\hline
\end{tabular}

The half-life of CP-4126 after iv administration varied between 0.05 and $0.07 \mathrm{~h}$, that of gemcitabine between 1.7 and $3.4 \mathrm{~h}$ and that of $\mathrm{dFdU}$ between 10.8 and $11.2 \mathrm{~h}$ for doses of CP-4126 varying from 2 to $6 \mathrm{mg} / \mathrm{kg}$ 
nucleoside carrier transport decreased the sensitivity of murine and human leukemia cells to cytarabine, but not to an elaidic acid derivative [13], decreased nucleoside transport activity might be a mechanism of resistance to cytarabine. Membrane passage does not seem a limiting factor in vitro for CP-4126, however, the lipophilicity of CP-4126 seems an advantage when uptake in the tumor is limited [40]. Moreover, possibly CP-4126 might act as a depot form similar to the lipophilic analogs of cytarabine [13]. Preliminary data confirmed this observation [41]. CP4126 showed a similar activity as gemcitabine itself; however, due to their nature a different administration schedule might be of advantage. Several clinical studies show a clear dependence of gemcitabine for an active transport system: at a low tumoral expression of ENT the survival of patients with pancreatic cancer was shorter than in patients with a high expression, measured either by PCR [42] or immunohistochemistry [43]. For such patients CP4126, which bypasses ENT mediated uptake, could be an active alternative.

Compared to gemcitabine, CP-4126 showed a similar growth inhibition pattern to published values for gemcitabine, with a Pearson correlation coefficient with a similar degree of correlation with topoisomerase inhibitors and DNA-antimetabolites. Since the COMPARE correlation coefficient with gemcitabine was below 0.8 , but still quite high, it probably follows a similar mode of action. However, additional mechanisms of action can not be excluded, e.g. the released elaidic acid might have a separate effect on cells. Further studies concentrated on the in vivo activity of CP-4126 against xenografts. When given ip, CP-4126 proved to be equally active or more active than gemcitabine in human tumors of different histological origin, but for none of the models a deficiency of ENT was reported. Moreover, CP-4126 was well tolerated as an oral drug with an impressive activity combined with a mild toxicity profile in mice bearing a colon cancer xenograft. Both activity and toxicity were dose and schedule dependent, which was in contrast to gemcitabine, which was highly toxic as an oral drug.

In conclusion, CP-4126 is an interesting gemcitabine derivative possibly mediating cytotoxicity through transporter independent membrane passage and self-potentiation by inhibition of degradation of gemcitabine. CP-4126 showed equal antitumor activity to gemcitabine in various xenograft models. Furthermore, equal antitumor activity was observed when oral administration was compared to intraperitoneal administration. It was previously shown that gemcitabine itself has no activity and it has a variable and low bioavailability when administered orally in mice [32]. Considering the recent trend to treat patients with variants of cytostatic agents that can be administered orally (e.g. Capecitabine, as oral 5-fluorouracil and the development of oral taxanes), CP-4126 might be a future oral alternative for gemcitabine.

Acknowledgements We would like to thank Britta Büttner and Svetlana Gromova for their excellent technical support in performing the animal experiments and Daphne Voorn, Lizzy Comijn, Karin Kuipers and Kees Smid for their contribution to the in vitro experiments.

Open Access This article is distributed under the terms of the Creative Commons Attribution Noncommercial License which permits any noncommercial use, distribution, and reproduction in any medium, provided the original author(s) and source are credited.

\section{References}

1. Lister TA, Rohatiner AZ (1982) The treatment of acute myelogenous leukemia in adults. Semin Hematol 19:172-192

2. Wolff RA (2007) Chemotherapy for pancreatic cancer: from metastatic disease to adjuvant therapy. Cancer J 13:175-184

3. Ramalingam S, Belani C (2008) Systemic chemotherapy for advanced non-small cell lung cancer: recent advances and future directions. Oncologist 13(Suppl 1):5-13

4. Abbruzzese JL (2002) New applications of gemcitabine and future directions in the management of pancreatic cancer. Cancer 95:941-945

5. Heinemann V, Hertel LW, Grindey GB et al (1988) Comparison of the cellular pharmacokinetics and toxicity of $2^{\prime}, 2^{\prime}$-difluorodeoxycy tidine and 1-beta-D-arabinofuranosylcytosine. Cancer Res 48:40244031

6. Ross DD, Chen SR, Cuddy DP (1990) Effects of 1-betaD-arabinofuranosylcytosine on DNA replication intermediates monitored by $\mathrm{pH}$-step alkaline elution. Cancer Res 50:2658-2666

7. Ross DD, Cuddy DP (1994) Molecular effects of $2^{\prime}, 2^{\prime}$-difluorodeox ycytidine (Gemcitabine) on DNA replication in intact HL-60 cells. Biochem Pharmacol 48:1619-1630

8. Ruiz van Haperen V, Veerman G, Vermorken JB et al (1993) 2',2'Difluoro-deoxycytidine (gemcitabine) incorporation into RNA and DNA of tumour cell lines. Biochem Pharmacol 46:762-766

9. Molina-Arcas M, Trigueros-Motos L, Casado FJ et al (2008) Physiological and pharmacological roles of nucleoside transporter proteins. Nucleosides Nucleotides Nucleic Acids 27:769-778

10. Griffith DA, Jarvis SM (1996) Nucleoside and nucleobase transport systems of mammalian cells. Biochim Biophys Acta 1286:153-181

11. Mackey JR, Mani RS, Selner M et al (1998) Functional nucleoside transporters are required for gemcitabine influx and manifestation of toxicity in cancer cell lines. Cancer Res 58:4349-4357

12. Gati WP, Paterson AR, Larratt LM et al (1997) Sensitivity of acute leukemia cells to cytarabine is a correlate of cellular es nucleoside transporter site content measured by flow cytometry with SAENTA-fluorescein. Blood 90:346-353

13. Breistol K, Balzarini J, Sandvold ML et al (1999) Antitumor activity of P-4055 (elaidic acid-cytarabine) compared to cytarabine in metastatic and s.c. human tumor xenograft models. Cancer Res 59:2944-2949

14. Bergman AM, Kuiper CM, Voorn DA et al (2004) Antiproliferative activity and mechanism of action of fatty acid derivatives of arabinofuranosylcytosine in leukemia and solid tumor cell lines. Biochem Pharmacol 67:503-511

15. Dueland S, Aamdal S, Lind MJ et al (2008) Intravenous administration of CP-4055 (ELACYTtrade mark) in patients with solid tumours. A phase I study. Acta Oncol 48:137-145 
16. Brouwer M, Smets LA, Jongsma AP (1983) Isolation and characterization of subclones of L1210 murine leukemia with different sensitivities to various cytotoxic agents. Cancer Res 43:2884-2888

17. Lacaze N, Gombaud-Saintonge G, Lanotte M (1983) Conditions controlling long-term proliferation of Brown Norway rat promyelocytic leukemia in vitro: primary growth stimulation by microenvironment and establishment of an autonomous Brown Norway 'leukemic stem cell line'. Leuk Res 7:145-154

18. Lu Y, Han J, Scanlon KJ (1988) Biochemical and molecular properties of cisplatin-resistant A2780 cells grown in folinic acid. J Biol Chem 263:4891-4894

19. Ruiz van Haperen V, Veerman G, Eriksson S et al (1994) Development and molecular characterization of a $2^{\prime}, 2^{\prime}$-difluorodeox ycytidine-resistant variant of the human ovarian carcinoma cell line A2780. Cancer Res 54:4138-4143

20. Bergman AM, Eijk PP, Ruiz van Haperen V et al (2005) In vivo induction of resistance to gemcitabine results in increased expression of ribonucleotide reductase subunit M1 as the major determinant. Cancer Res 65:9510-9516

21. Smid K, Bergman AM, Eijk PP et al (2006) Micro-array analysis of resistance for gemcitabine results in increased expression of ribonucleotide reductase subunits. Nucleosides Nucleotides Nucleic Acids 25:1001-1007

22. Balzarini J, Schols D, Neyts J et al (1991) Alpha-(1-3)- and alpha(1-6)-D-mannose-specific plant lectins are markedly inhibitory to human immunodeficiency virus and cytomegalovirus infections in vitro. Antimicrob Agents Chemother 35:410-416

23. Bergman AM, Pinedo HM, Jongsma AP et al (1999) Decreased resistance to gemcitabine $\left(2^{\prime}, 2^{\prime}\right.$-difluorodeoxycytidine) of cytosine arabinoside-resistant myeloblastic murine and rat leukemia cell lines: role of altered activity and substrate specificity of deoxycytidine kinase. Biochem Pharmacol 57:397-406

24. Skehan P, Storeng R, Scudiero D et al (1990) New colorimetric cytotoxicity assay for anticancer-drug screening. J Natl Cancer Inst 82:1107-1112

25. Keepers YP, Pizao PE, Peters GJ et al (1991) Comparison of the sulforhodamine B protein and tetrazolium (MTT) assays for in vitro chemosensitivity testing. Eur J Cancer 27:897-900

26. Peters GJ, Wets M, Keepers YP et al (1993) Transformation of mouse fibroblasts with the oncogenes H-ras or trk is associated with pronounced changes in drug sensitivity and metabolism. Int $\mathbf{J}$ Cancer 54:450-455

27. Monks A, Scudiero D, Skehan P et al (1991) Feasibility of a highflux anticancer drug screen using a diverse panel of cultured human tumor cell lines. J Natl Cancer Inst 83:757-766

28. Shoemaker RH (2006) The NCI60 human tumour cell line anticancer drug screen. Nat Rev Cancer 6:813-823

29. Ruiz van Haperen V, Veerman G, Braakhuis BJ et al (1993) Deoxycytidine kinase and deoxycytidine deaminase activities in human tumour xenografts. Eur J Cancer 29A:2132-2137
30. Fichtner I, Slisow W, Gill J et al (2004) Anticancer drug response and expression of molecular markers in early-passage xenotransplanted colon carcinomas. Eur J Cancer 40:298-307

31. Veerman G, Ruiz van Haperen V, Vermorken JB et al (1996) Antitumor activity of prolonged as compared with bolus administration of $2^{\prime}, 2^{\prime}$-difluorodeoxycytidine in vivo against murine colon tumors. Cancer Chemother Pharmacol 38:335-342

32. Zajchowski DA, Biroc SL, Liu HL et al (2005) Anti-tumor efficacy of the nucleoside analog 1-(2-deoxy-2-fluoro-4'-thio-betaD-arabinofuranosyl) cytosine (4'-thio-FAC) in human pancreatic and ovarian tumor xenograft models. Int J Cancer 114:1002-1009

33. Bengala C, Guarneri V, Giovannetti E et al (2005) Prolonged fixed dose rate infusion of gemcitabine with autologous haemopoietic support in advanced pancreatic adenocarcinoma. Br J Cancer 93:35-40

34. Schwendener RA, Friedl K, Depenbrock H et al (2001) In vitro activity of liposomal N4octadecyl-1-beta-D-arabinofuranosylcyto sine (NOAC), a new lipophilic derivative of 1-beta-D-arabinofur anocylcytosine on biopsized clonogenic human tumor cells and hematopoietic precursor cells. Invest New Drugs 19:203-210

35. Choe YH, Conover CD, Wu D et al (2002) Anticancer drug delivery systems: multi-loaded N4-acyl poly(ethylene glycol) prodrugs of ara-C. II. Efficacy in ascites and solid tumors. J Control Release 79:55-70

36. Fanucchi MP, Watanabe KA, Fox JJ et al (1986) Kinetics and substrate specificity of human and canine cytidine deaminase. Biochem Pharmacol 35:1199-1201

37. Bouffard DY, Laliberte J, Momparler RL (1993) Kinetic studies on 2',2'-difluorodeoxycytidine (Gemcitabine) with purified human deoxycytidine kinase and cytidine deaminase. Biochem Pharmacol 45:1857-1861

38. Bergman AM, Pinedo HM, Peters GJ (2002) Determinants of resistance to $2^{\prime}, 2^{\prime}$-difluorodeoxycytidine (gemcitabine). Drug Resist Update 5:19-33

39. Yonemori K, Ueno H, Okusaka T et al (2005) Severe drug toxicity associated with a single-nucleotide polymorphism of the cytidine deaminase gene in a Japanese cancer patient treated with gemcitabine plus cisplatin. Clin Cancer Res 11:2620-2624

40. Galmarini CM, Myhren F, Sandvold ML (2008) CP-4055 and CP4126 are active in ara-C and gemcitabine-resistant lymphoma cell lines. Br J Haematol 144:273-275

41. Adema A, Smid K, Losekoot N et al (2008) Fatty acid derivatives of cytarabine and gemcitabine, CP-4055 and CP-4126, show a prolonged cellular retention compared to the parent drug Proc Amer Assoc. Cancer Res 49:1365 (\#5740)

42. Farrell JJ, Elsaleh H, Garcia M et al (2009) Human equilibrative nucleoside transporter 1 levels predict response to gemcitabine in patients with pancreatic cancer. Gastroenterology 136:187-195

43. Giovannetti E, Del Tacca M, Mey V et al (2006) Transcription analysis of human equilibrative nucleoside transporter-1 predicts survival in pancreas cancer patients treated with gemcitabine. Cancer Res 66:3928-3935 